\title{
Bel ve boyun ağrılarında elektronöromiyografi
}

\author{
Using electroneuromyography in waist and neck pain
}

\author{
Arzu Yağız On \\ Ege Üniversitesi Tıp Fakültesi Fizik Tedavi ve Rehabilitasyon Anabilim Dalı, İzmir
}

Bel ve boyun ağrılarında elektrodiyagnostik incelemeler, özellikle radikülopati varlığının gösterilme-sinde, dışlanmasında ve ayırıcı tanısında değerlidir. Bu yazıda, radikülopatilerin değerlendirilmesinde kullanılan elektrodiyagnostik incelemeler, bu incelemelerin endikasyonları, radikülopatili hastaların değerlendirilmesindeki rolleri, güçlü ve kısıtlı yönleri, duyarlılık ve özgünlükleri ile ilgili bilgiler gözden geçirilecektir.

Anahtar sözcükler: elektromiyografi; elektrodiagnostik incelemeler; radikülopati
Electrodiagnostic examinations are valuable in diagnosing, excluding and differentiating radiculopathies in patients with neck and waist pain. In this article, electrodiagnostic techniques that have been used for evaluating radiculopathies, the indications of electrodiagnostic studies and their role in the evalua-tion of the patients with radiculopathy, strengths and limitations of these studies, available information about their sensitivities and specificities will be reviewed.

Key words: electromyography; electrodiagnostic examinations; radiculopathy
E lektrodiagnostik (ED) incelemeler, kas ve sinirlerin elektriksel aktivitelerinin ölçümü yoluyla alt motor nöron hastalıklarının değerlendirilmesini sağlayan tanısal yöntemlerdir. Bu incelemeler, periferik sinir hastalıkları, radikülopati, kas hastalıkları, motor nöron hastalıkları ve motor son plak hastalıklarının tanısında ve birbirlerinden ayırt edilmesinde, lezyonun lokalize edilmesinde, şiddet ve yaygınlığının belirlenmesinde ve prognozunun tahmininde önemli bilgiler verir. Rutin bir ED inceleme, duysal ve motor sinir iletim çalışmalarını (elektronörografi -ENG) ve konvansiyonel iğne elektromiyografisini (EMG) içerir. Bu teknikler sıklıkla birlikte gerçekleştirilir ve birbirlerini tamamlar. Bu nedenle, ikisi birlikte elektronöromiyografi (ENMG) olarak adlandırılır. Bazen bunlara, refleks çalışmalar, geç yanıtlar, somatosensöriyel ve motor uyartılmış potansiyeller, tek lif ve makro EMG incelemeleri, repetitif uyarı, sempatik deri yanıtları ve $\mathrm{R}-\mathrm{R}$ interval analizi gibi diğer teknikler de eklenebilir.

Bel ve boyun ağrılarında ED incelemeler, özellikle radikülopati varlığının gösterilmesinde, dışlanmasında ve ayırıcı tanısında değerlidir. Radikülopatiler, ENMG laboratuvarlarına en sık başvurulan durumlardan biridir. Ancak, son yıllarda manyetik rezonans (MR) görüntüleme yöntemlerinin yaygınlaşmasıyla, bu incelemelerin tanıdaki yararılı̆̆ı sorgulanmaya başlamıştır. Bununla birlikte, radikülopati tanısında altın standart bulunmamaktadır. Bu nedenle, tanıda klinik bulgular, radyografik incelemeler ve ENMG birbirinin yerine geçen değil, birbirini tamamlayan testlerdir.

Burada, bel ve boyun ağrılı hastalarda radikülopati varlığının gösterilmesinde, dışlanmasında ve ayırıcı tanısında kullanılan ED incelemeler, bu incelemelerin endikasyonları, tanısal değerleri ve kısıtlııkları gözden geçirilecektir.

\section{RADIKÜLOPATI DEĞERLENDIRMESINDE KULLANILAN ED INCELEMELER}

ED incelemelerin yararı büyük ölçüde incelemeyi yapan kişinin ustalık, deneyim, bilgi ve becerisine bağlıdır. Diğer bütün tanısal testlerde olduğu gibi, çalışmanın

- Illetişim adresi: Prof. Dr. Arzu Yağız On, Ege Üniversitesi Tıp Fakültesi Fizik Tedavi ve Rehabilitasyon Anabilim Dalı, İzmir Tel: 0232 - 3903682 e-posta: arzuon@gmail.com

- Geliş tarihi: 20 Șubat 2017 Kabul tarihi: 20 Şubat 2017 
doğru planlanması, doğru gerçekleştirilmesi ve doğru yorumlanması, doğru sonuçların elde edilmesinde en önemli faktördür. ED incelemeler, fizik muayenenin bir uzantısıdır. Hangi hastada hangi incelemelerin yapılacağı, hastanın klinik bulgularına göre kişiye özel tasarlanır ve elde edilen her bulguya göre her aşamada yeniden yönlendirilir. Bu nedenle, incelemeyi isteyen klinisyen tarafindan, hasta ile ilgili ayrıntılı tıbbi bilgileri, fizik muayene bulgularını ve ED incelemenin ne amaçla istendiğini belirten istek kağıdı düzenlenmelidir.

Radikülopatilerin değerlendirilmesinde en önemli ED inceleme, iğne EMG'dir. Bu, kas içine yerleştirilen özel iğne elektrodlar yoluyla kasa ait elektriksel potansiyelleri inceleyen, nörojenik ve miyojenik tutuluşların ayırt edilmesini sağlayan bir yöntemdir. İğne EMG, lezyonun belli bir radiks düzeyine lokalize edilmesini sağlar ve lezyonun şiddeti, yaygınlığı ve süresi ile ilgili önemli bilgiler verir; ayırıcı tanıda da kritik öneme sahiptir.

İzole radikülopati tanısında temel EMG kriteri; aynı miyotomdan, ancak farklı periferik sinirden innerve olan en az iki ekstremite kasında nörojenik anormalliklerin saptanması, diğer radikslerden innerve olan kasların normal olması ve bu bulguları açıklayacak başka bir elektrofizyolojik anormalliğin olmamasıdır. ${ }^{[1-3]}$ Buna göre, bir miyotoma ait en az iki kas incelenmeli, tek kastaki anormallik asla radikülopati lehine değerlendirilmemelidir. Ek olarak, aynı miyotoma ait olan, ancak farklı periferik sinirlerden innerve olan kasların incelenmesi gereklidir. Örneğin, C7 radikülopatide, $\mathrm{C} 7$ radiksinden innerve olan radyal ve median sinir innervasyonlu kaslarda anormallik gösterilmelidir. Radikülopatinin dışlanması için de en az iki kasın normal olduğu gösterilmelidir. Ayırıcı tanı için de, bölgedeki komşu kaslar ve aynı periferik sinirden innerve olup farklı radikslerden innerve olan kaslar incelenmelidir. Ekstremite kaslarına ek olarak, paraspinal kasların iğne EMG incelemesi, radikülopati incelemesinin duyarlılığını arttıran önemli bir incelemedir. ${ }^{[4-6]} \mathrm{Bu}$ incelemenin diğer bir önemi de, pleksus proksimalindeki hasarı göstermesi nedeniyle, radikülopatinin pleksus veya periferik sinir düzeyindeki daha distal bir lezyondan ayırt edilmesini sağlamasıdır. Dolayısıyla, radikülopati tanısına güvenilir ve doğru bir şekilde ulaşmak için, en sık görülen radikülopati düzeyleri için ilgili miyotomlara ait birçok kasın ve paraspinal kasların incelenmesi gereklidir (Tablo 1 ve Tablo 2). Incelenen kas sayısının az olması EMG duyarlıı̆̆ını düşürmektedir. Ancak, EMG invaziv bir inceleme olduğundan, mümkün olan en az sayıda kas incelenerek tanıya ulaşmak önemlidir. ${ }^{[4-6]}$

Radikülopati varlığında, iğne EMG ile ilgili kaslarda saptanan en önemli nörojenik anormallik, akut ve/veya kronik denervasyon bulgularıdır. Radiksin miyotomal dağılımına uyan ekstremite kaslarında ve paraspinal kaslarda pozitif keskin dalga ve fibrilasyon potansiyelleri gibi denervasyon potansiyellerinin görülmesi, en önemli ve güvenilir bulgudur. Ancak, aksonal kayıpla sonlanan tüm lezyonlarda, EMG'de patolojik bulguların çıkması, lezyon yeri ve kas arasındaki mesafeye bağlı olarak belirli bir zaman alır. Denervasyon potansiyelleri ilk olarak (en erken yedi günde) paraspinal kaslarda görülür. İki-üç haftada proksimal ekstremite kaslarında, 3-4 haftada distal ekstremite kaslarında denervasyon potansiyelleri saptanır. Denervasyon potansiyellerinin kaybolması da proksimalden distale doğrudur. ${ }^{[7-8]}$ Bu nedenle, EMG istenirken ve sonuçlar yorumlanırken bu zamansal özelliğe dikkat edilmelidir. Kronik radikülopatilerde ise, ilgili kaslarda denervasyon potansiyelleri gözlenmezken, kronik nörojenik motor ünit potansiyeli (MÜP) değişiklikleri görülür.

Sinir iletim çalışmaları (Siç), radikülopatilerde tanıdan ziyade ayırıcı tanıda önemlidir. Çünkü pür radikülopatilerde, lezyon duyusal gangliyon öncesinde olduğundan, distal duyusal iletim çalışmaları normaldir. Bu bulgu, pleksopati ve periferik nöropati ayırımında önemlidir. Duyusal iletim çalışmalarında belirgin anormallik saptandığında, dorsal kök gangliyon distalindeki bir lezyon varlığı (pleksopati, periferik nöropati, tuzak nöropati gibi) araştırılmalıdır. Radikülopatide motor ileti hızları normal iken, ciddi akson kaybında veya çok düzeyde kök hasarında, ilgili kastan elde edilen Birleşik Kas Aksiyon Potansiyeli (BKAP) amplitüdü küçülebilir. Radikülopati ön tanısıyla gelen bir hastada sinir iletim çalışmalarının hangi yoğunlukta gerçekleştirileceği kararı, klinik bulgular ve ayırıcı tanıda akla gelen diğer durumlar göz önünde bulundurularak verilmelidir.

\section{RADIKÜLOPATILERDE ENMG ENDIKASYONLARI}

\section{Radikülopati Varlığının Gösterilmesi ve/veya Dışlanması}

Servikal veya lomber radikülopatiyi düşündüren belirti ve bulgularla başvuran ve klinik bulguların tanıda yeterli olduğu olgularda ED incelemelerin yeri tartışılır olmakla birlikte, bu olgularda radikülopati tanısının doğrulanmasında, lezyonun şiddetinin ve yaygınlığının, süresinin belirlenmesinde yararlı olabilir. Diğer yandan, bazı olgularda klinik bulgular radikülopati varlığını ve lezyon düzeyini ortaya koymakta yetersiz kalabilir. Radiks innervasyonlarındaki örtüşmeler nedeniyle, refleks, motor ve duyu bulgularında değişkenlik, klinik tanıyı güçleştirebilir. Yine, bazı hastalarda radyolojik incelemeler de yetersiz kalabilir. Yapılan çalışmalar, klinik bulgularla 
Tablo 1. Üst ekstremite miyotomları

\begin{tabular}{|c|c|c|c|c|c|}
\hline Kas (sinir) & $\mathrm{C} 5$ & $\mathrm{C} 6$ & C7 & $\mathrm{C} 8$ & T1 \\
\hline Rhomboid (n.scapulodorsalis) & ++ & & & & \\
\hline Supraspinatus/infraspinatus (n.suprascapularis) & ++ & + & & & \\
\hline Deltoid (n.axillaris) & ++ & + & & & \\
\hline Biceps (n.musculocutaneous) & ++ & ++ & & & \\
\hline Triceps (n.radialis) & & + & ++ & + & \\
\hline Ext. Carpi radialis (n.radialis) & & ++ & ++ & & \\
\hline Ext. İndicis proprius (n.radialis) & & & ++ & ++ & \\
\hline Flx. Carpi ulnaris (n.ulnaris) & & & + & ++ & \\
\hline 1. dorsal interosseöz (n.ulnaris) & & & & + & ++ \\
\hline Pronator teres (n.medianus) & & ++ & ++ & & \\
\hline Flx. Carpi radialis (n.medianus) & & + & ++ & & \\
\hline Flx. pollicis longus (n.medianus) & & & & ++ & + \\
\hline Abd. pollicis brevis (n.medianus) & & & & + & ++ \\
\hline
\end{tabular}

++ majör innervasyon

+ minör innervasyon

Tablo 2. Alt ekstremite miyotomları

\begin{tabular}{|c|c|c|c|c|c|c|}
\hline Kas (sinir) & L2 & L3 & L4 & L5 & S1 & S2 \\
\hline iliopsoas (lomber pleksus/n.femoralis) & ++ & ++ & + & & & \\
\hline Adduktor kaslar (n.obturatorius) & ++ & ++ & ++ & & & \\
\hline Vastus medialis/rectus femoris (n.femoralis) & + & ++ & ++ & & & \\
\hline Tensor fascia lata (n.gluteus superior) & & & & ++ & ++ & \\
\hline Gluteus medius (n.gluteus superior) & & & & ++ & ++ & \\
\hline Gluteus maximus (n.gluteus inferior) & & & & + & ++ & + \\
\hline Semitendinosus/semimembranosus (n.tibialis) & & & & ++ & ++ & + \\
\hline Biceps femoris uzun başı (n.tibialis) & & & & + & ++ & + \\
\hline Biceps femoris kısa başı (n.peroneus communis) & & & & + & ++ & + \\
\hline Tibialis anterior (n.peroneus profundus) & & & + & ++ & & \\
\hline Ext. hallucis longus (n.peroneus profundus) & & & & ++ & + & \\
\hline Peroneus longus (n.peroneus superficialis) & & & & ++ & + & \\
\hline Ext. digitorum brevis (n.peroneus profundus) & & & & ++ & + & \\
\hline Gastrocinemius medialis (n.tibialis) & & & & & ++ & ++ \\
\hline Abd. hallucis (n.tibialis) & & & & & ++ & ++ \\
\hline
\end{tabular}


radyografik bulgular arasında uyumsuzluk olduğunu göstermiştir. ${ }^{[9,10]}$ Daha da ötesi, MR ile asemptomatik kişilerde özellikle lomber bölgede sık anormal bulgular saptanmaktadır. Bu nedenle, MR'de saptanan yapısal değişikliklerin sinir radiksinde fizyolojik anormalliğe neden olup olmadığının gösterilmesinde ED incelemeler yararlıdır. MR ile ilgili bir diğer sorun da, yapısal olmayan radikülopatilerde (diyabetik, inflamatuvar, enfeksiyöz, paraneoplastik) MR'nin kliniği desteklememesidir. ${ }^{[11,12]}$ Bu nedenle, klinik olarak radikülopati ile uyumlu olan ancak MR negatif olan hastalarda, MR ile gösterilemeyen fizyolojik anomalileri saptamak amacıyla ED incelemeler endikedir. Klinik bulgular ve MR bulgularının uyumsuz olduğu durumlarda da, klinik izlenimi güçlendirmek ve en çok etkilenen radiks düzeyinin belirlenebilmesi amacıyla ED incelemelere başvurulabilir.

\section{Ayırıcı Tanı}

Klinik semptom ve bulgulara neden olabilecek diğer nörolojik nedenlerin ortaya konması/dışlanmasında ED incelemeler kritik öneme sahiptir. Erken dönemde veya hafif tutuluş olan olgularda, radikülopatinin klinik olarak pleksopati veya mononöropatiden ayırımı güç olabilir. L5 radikülopati ile, peroneal sinir nöropatisi, lumbosakral pleksopati veya siyatik sinir nöropatisi karışabilir. Benzer şekilde, C5-6 radikülopati ile brakiyal pleksopati ve karpal tünel sendromu, C7 radikülopati ile brakiyal pleksopati ve radyal sinir nöropatisi, C8-T1 radikülopati ile brakiyal pleksopati ve ulnar sinir nöropatisi karışabilir. Yine, bazı olgularda çok düzeyli lomber radikülopati ile polinöropati ve motor nöron hastalığı ayırımı için ED incelemeler gerekli olur.

\section{Prognoz Tahmini}

Tartışmalı olmakla birlikte, ENMG incelemesi normal olan olguların prognozunun patolojik olan olgulara göre daha iyi olduğunu gösteren az sayıda çalışma bulunmaktadır. ${ }^{[13]}$

\section{Tedaviye Yanıtın Tahmini}

Tartışmalı olmakla birlikte, az sayıda çalışmada, EMG-pozitif radikülopati olgularının epidural steroid enjeksiyonlarına ve cerrahi tedaviye daha iyi yanıt verdiği gösterilmiştir. ${ }^{[14-16]}$

\section{RADIKÜLOPATI TANISINDA EMG INCELEMELERININ DUYARLILIĞI}

Servikal veya lomber radikülopati tanısında ENMG incelemelerinin duyarlılığının düşük olması, en önemli kısıtlılığıdır. Ancak, radikülopati tanısında altın standart olmaması nedeniyle, duyarlılığı hakkında net bilgi bulunmamaktadır. Radikülopati tanısında kullanılan kriterlere ve incelenen kas sayısına bağlı olarak, duyarlılık \%30-95 arasında değişmektedir. ${ }^{[10,17-19]}$ Günlük pratikte de, klinik bulguları radikülopati ile uyumlu olduğu halde EMG incelemesi normal olan olgularla sıklıkla karşılaşılmaktadır.

Optimal olarak gerçekleştirilmiş bir iğne EMG incelemesinin duyarlılığını düşüren başlıca nedenler şunlardır:

1. Akut radikülopatide (2-3 haftadan önce) ekstremite kaslarının iğne EMG incelemesi normaldir.

2. Pür duyusal radikülopatilerde iğne EMG normaldir. EMG sadece motor sinir sistemindeki değişikleri gösterebilir. Bu nedenle, ağrı, parestezi, uyuşma gibi duyusal yakınmaları olan, ancak motor defisitin eşlik etmediği pür duyusal radikülopatilerde EMG incelemesi normaldir. ${ }^{[10]}$

3. Demiyelinizasyonla giden veya çok ılımlı akson kaybıyla giden radikülopatilerde, iğne EMG incelemesi normaldir. Çünkü EMG, sadece sinirin aksonal bileşenindeki hasarı gösterebilir. Bu durumda, klinik olarak kas kuvvet kaybı gelişmiş motor radikülopatilerde bile iğne EMG normal olacaktır.

4. Denervasyonun reinnervasyonla dengelendiği durumlarda, denervasyon potansiyelleri görülmeyebilir.

5. Paraspinal kasların sinir köküne yakınlı̆̆ı nedeniyle, erken dönemde ilk olarak bu kaslarda denervasyon görülürken, reinnervasyon sonucu ilk normale dönen kaslar da bu kaslardır. Bu nedenle, kronik radikülopatilerde paraspinal EMG normal olabilir.

6. Özellikle erken dönemdeki radikülopatilerin büyük bir kısmında, primer duyusal ve miyelin bileşeni etkilendiğinden, bu tür radikülopatilerde iğne EMG incelemeleri normal bulunur. Duyarlılık, radikülopati yakınmaları olan ancak objektif klinik bulgusu olmayan hastalarda düşük iken, kesin ve şiddetli radikülopati olgularında ve motor kaybın olduğu olgularda daha yüksek bulunmaktadır. Bu nedenle, EMG incelemesinin normal olması radikülopati varlığını ekarte ettirmez. Bu durum, EMG incelemesini yapan kadar, tetkiki isteyen hekim tarafindan da dikkate alınmak zorundadır.

Bazı durumlarda da, radiks lezyonunun seviyesi tam olarak belirlenemez. ${ }^{[1,2]}$ Bunun nedenleri: 
1. Birçok kasın primer olarak hangi kökten innerve olduğu tam açıklığa kavuşmamıştır. Daha da ötesi, kişiler arası farklılıklar bulunmaktadır.

2. Üst lomber radikülopatilerde kesin düzeyin belirlenmesi güçtür. Bunun en önemli nedeni, L23-4 düzeylerinde yoğun miyotomal örtüşmelerin söz konusu olmasıdır.

\section{RADIKÜLOPATI TANISINDA EMG INCELEMELERININ ÖZGÜNLÜĞÜ}

EMG incelemelerinin, duyarlılığı arzu edilenden düşük olmakla birlikte, özgünlüğü çok yüksektir. ${ }^{[10,20,21]}$ $\mathrm{Bu}$ özellik, iğne EMG incelemelerinin en güçlü yönüdür. Radikülopatilerde gereksiz tedavilerden kaçınılmasında özgünlüğün duyarlılıktan daha önemli olması, EMG'nin değerini ve önemini arttıran bir unsurdur. Ancak, gerek servikal gerekse lomber radikülopatilerde, nadiren yalancı pozitif sonuçlar elde edilebilir. Özellikle polifazi artışı gibi ılımlı nörojenik anormalliklerin tek başına tanıda kullanılmaları, yalancı pozitiflik oranının artmasına, bu da gereksiz tedavilere neden olabilir. Yine, paraspinal kasların iğne EMG incelemesinin özgünlüğü düşüktür. Bu kaslarda anormal spontan aktivite asemptomatik sağlıklı kişilerde de saptanabilir. Yapılan çalışmalarda, bu oranın \%14,5-42 arasında değiştiği, özellikle 60 yaş üzerinde arttığı bulunmuştur. ${ }^{[22-24]}$ Motor nöron hastalığı, diyabet, polimiyozit, posterior ramus metastazı gibi diğer durumlarda da, paraspinal kaslarda denervasyon saptanabilir. Yine posterior spinal cerrahiden yıllar sonra bile denervasyon potansiyelleri kayıtlanabilir. Bu durum, laminektomi sonrası yapılan EMG'de sorun yaratır. Bu durumda, hastanın ameliyat öncesi EMG'sinin mevcut olması önem taşır. Eğer operasyon sonrası ilk 10 günde yapılan EMG'de denervasyon varsa, bu denervasyonun eski lezyona bağlı olduğu söylenebilir. Ancak, laminektomi sonrası uzun süreli semptomsuz dönemden sonra yakınmalar ortaya çıkarsa, EMG yeni bir disk protrüzyonu ile epidural veya subaraknoid yapışıklıkları ayırt edemez. Bu durumda MR daha üstündür. Bu kısıtlılıklardan dolayı, özellikle ileri yaşlardaki kişilerde tek anormalliğin paraspinal kaslarda saptanması durumunda,s radikülopati tanısı konulmasında dikkatli olunmalıdır.

\section{KAYNAKLAR}

1. Hakimi K, Spanier D. Electrodiagnosis of cervical radiculopathy. Phys Med Rehabil Clin N Am 2013;24(1):112. Crossref

2. Barr K. Electrodiagnosis of Lumbar Radiculopathy. Phys Med Rehabil Clin N Am 2013;24(1):79-91. Crossref
3. AAEM. Practice parameter for needle electromyographic evaluation of patients with suspected cervical radiculopathy. Muscle Nerve 1999(Suppl 8):209-21.

4. Lauder TD, Dillingham TR, Huston CW, Chang AS, Belandres PV. Lumbosacral radiculopathy screen. Optimizing the number of muscles studies. Am J Phys Med Rehabil 1994;73(6):394-402.

5. Dillingham TR, Lauder TD, Andary M, Kumar S, Pezzin LE, Stephens RT, Shannon S. Identification of cervical radiculopathies: optimizing the electromyographic screen. Am J Phys Med Rehabil 2001;80(2):84-91.

6. Dillingham TR, Lauder TD, Andary M, Kumar S, Pezzin LE, Stephens RT, Shannon S. Identifying lumbosacral radiculopathies: an optimal electromyographic screen. Am J Phys Med Rehabil 2000;79(6):496-503.

7. Pezzin LE, Dillingham TR, Lauder TD, Andary M, Kumar S, Stephens RR, Shannon S. Cervical radiculopathies: relationship between symptom duration and spontaneous EMG activity. Muscle Nerve 1999;22(10):1412-8.

8. Dillingham TR, Pezzin LE, Lauder TD, Andary M, Kumar S, Stephens RT, Shannon S. Symptom duration and spontaneous activity in lumbosacral radiculopathy. Am J Phys Med Rehabil 2000;79(2):124-32.

9. Weishaupt D, Zanetti M, Hodler J, Boos N. MR imaging of the lumbar spine: prevalence of intervertebral disk extrusion and sequestration, nerve root compression, end plate abnormalities, and osteoarthritis of the facet joints in asymptomatic volunteers. Radiology 1998;209(3):661-6.

10. Kısmalı B, On AY, Kirazlı Y, Kısmalı E, Çapacı K, Akşit R. Comparison of clinical, electromyographic and magnetic resonance imaging findings in patients with mechanical low back pain. Ege Fiz Tıp Reh Derg 2000;6:33-9.

11. Ter Meulen BC, Rath JJ. Motor radiculopathy caused by varicella zoster virus without skin lesions('zoster sine herpete'). Clin Neurol Neurosurg 2010;112(10):933. Crossref

12. Kim SJ, Kim WR, Kim HS, Park HW, Cho YW, Jang SH, Hwang SJ, Ahn SH. Abnormal spontaneous activities on needle electromyography and their relation with pain behavior and nerve fiber pathology in a rat model of lumbar disc herniation. Spine (Phila Pa 1976) 2011;36(24):E1562-7. Crossref

13. Falck B, Nykvist F, Hurme M, Alaranta $H$. Prognostic value of EMG in patients with lumbar disc herniation -a five year follow up. Electromyogr Clin Neurophysiol 1993;33(1):19-26.

14. Annaswamy TM, Bierner SM, Chouteau W, Elliott AC. Needle electromyography predicts outcome after lumbar epidural steroid injection. Muscle Nerve 2012;45(3):346-55. Crossref

15. Spengler DM, Ouellette EA, Battie M, Zeh J. Elective discectomy for herniation of a lumbar disc. Additional experience with an objective method. J Bone Joint Surg Am 1990;72(2):230-7.

16. Alrawi MF, Khalil NM, Mitchell P, Hughes SP. The value of neurophysiological and imaging studies in predicting outcome in the surgical treatment of cervical radiculopathy. Eur Spine J 2007;16(4):495-500.

17. Albeck MJ, Taher G, Lauritzen M, Trojaborg W. Diagnostic value of electrodiagnostic tests in patients with sciatica. Acta Neurol Scand 2000;101(4):249-54.

18. Kuruoglu R, Oh SJ, Thompson B. Clinical and electromyographic correlations of lumbosacral radiculopathy. Muscle Nerve 1994;17(2):250-1.

19. Nardin RA, Patel MR, Gudas TF, Rutkove SB, Raynor EM. Electromyography and magnetic resonance imaging in the evaluation of radiculopathy. Muscle Nerve 1999;22(2):151-5. 
20. Tong HC. Specificity of needle electromyography for lumbar radiculopathy in 55- to 79-yr-old subjects with low back pain and sciatica without stenosis. Am J Phys Med Rehabil 2011;90(3):233-42. Crossref

21. Robinson LR. Electromyography, magnetic resonance imaging, and radiculopathy: it's time to focus on specifity. Muscle Nerve 1999;22(2);149-50.

22. Date ES, Kim B, Yoon JS, Park BK. Cervical paraspinal spontaneous activity in asymptomatic subjects. Muscle Nerve 2006;34(3):361-4.
23. Dates ES, Mar EY, Bugola MR, Teraoka JK. The prevalence of lumbar paraspinal spontaneous activity in asymptomatic subjects. Muscle Nerve 1996;19(3):350-4.

24. On AY, Öztürk C, Nusreti $H$, Akşit R. Lumbar paraspinal electromyography in subjects without low back pain. Ege Fiz Tip Reh Derg 1997;3:43-8. 